\title{
O saneamento rural no contexto brasileiro
}

Rachel Germiniani Resende

Sindynara Ferreira ${ }^{2}$

Luiz Flávio Reis Fernandes 3

\section{Resumo}

A exploração de recursos naturais e o crescente aumento da geração de subprodutos trazem consequências danosas para o homem e o meio ambiente. O saneamento é uma das formas de reverter esse quadro, pois promove a salubridade ambiental por meio do abastecimento público de água potável, coleta de efluentes e de resíduos, uso correto do solo, drenagem urbana, entre outros, com a finalidade de melhorar as condições de vida urbana e rural. 0 meio rural é caracterizado por populações com menor acesso às medidas de saneamento, com $25 \%$ de sua população vivendo em extrema pobreza. Ao longo dos anos foram criadas diversas políticas públicas com o objetivo de universalizar o acesso às ações de saneamento. Dessa forma, o presente trabalho pretendeu por meio de uma pesquisa de revisão bibliográfica verificar a situação acerca do saneamento básico no Brasil, com ênfase no saneamento rural. Para isto, foram utilizados como fontes de informações relevantes os principais órgãos públicos e privados, além de documentos do meio acadêmico. Conclui-se que a tendência é que o saneamento rural seja construído mais lentamente do que nas áreas urbanas devido à baixa concentração de pessoas em uma mesma área e por isso é necessária a difusão do conhecimento sobre saneamento como direito constitucional para que se torne uma construção participativa na qual a sociedade seja atuante nas demandas, promovendo melhorias na qualidade de vida.

Palavras-chave: Comunidades isoladas. Saúde. Salubridade.

\section{Introdução}

O homem é o único animal capaz de alterar o meio natural em que vive de forma drástica, criando um ambiente favorável à vida individual e coletiva. No decorrer de toda sua trajetória, ele vem modificando a natureza para diversos fins, como alimentação, moradia, vestuário, transporte, entre outros. De acordo com Brunner e Rechberger (2015), o homem pré-histórico movimentava anualmente cerca de seis toneladas por habitante de materiais, enquanto o homem moderno movimenta cerca de 86 toneladas de materiais por habitante no mesmo período apenas nas atividades domésticas e transporte. Se considerar todas as atividades necessárias, esse fluxo de materiais passa de 200 toneladas por ano. Dessa maneira, todo o progresso da sociedade é baseado no uso e exploração de diferentes recursos naturais (CARVALHO; OLIVEIRA, 2007). 0 intenso uso dos recursos naturais aliado ao aumento populacional e o consequente consumismo acarretaram diversas consequências, entre elas a degradação ambiental.

1 Instituto Federal de Educação, Ciência e Tecnologia do Sul de Minas Gerais (IFSULDEMINAS), Campus Inconfidentes, discente de Pós-Graduação em Gestão Ambiental (lato-sensu). rachelgresende@yahoo.com.br. Rua Geraldo Braz, 22. Bairro Jardim Ebenezer, Ouro Fino (MG). CEP: 37570-000.

2 IFSULDEMINAS, Campus Inconfidentes, professora e pesquisadora. sindynara.ferreira@ifsuldeminas.edu.br.

3 IFSULDEMINAS, Campus Inconfidentes, professor e pesquisador. luiz.flavio@ifsuldeminas.edu.br. 
Os resíduos que são lançados diariamente no ambiente podem gerar consequências negativas e muitas vezes irreversíveis à saúde humana e ambiental, resultando em contaminação do ar, água, solos, alimentos e a proliferação de vetores responsáveis por diversas doenças. Nesse sentido, o saneamento é uma ferramenta importante na mitigação ou reversão dos impactos negativos causados pelo homem no meio ambiente (PHILIPP, 2005).

Saneamento é o conjunto de medidas que visa preservar ou modificar as condições do meio ambiente com a finalidade de prevenir doenças e promover a saúde, melhorar a qualidade de vida da população, a produtividade do indivíduo e facilitar a atividade econômica (INSTITUTO TRATA BRASIL, 2016a). No Brasil o saneamento básico é um direito reconhecido pela Constituição Federal e determinado pela Política Nacional de Saneamento Básico - Lei n. 11.445/2007 - como o conjunto dos serviços, infraestrutura e instalações operacionais de abastecimento de água, esgotamento sanitário, limpeza urbana, drenagem urbana, manejos de resíduos sólidos e de águas pluviais (INSTITUTO TRATA BRASIL, 2016a). As ações de infraestrutura que constituem o saneamento, quando realizadas adequadamente, influenciam positivamente o bem-estar e a saúde das populações favorecidas, tornando o saneamento ambiental condição necessária à vida contemporânea, além de um direito fundamental dos cidadãos da sociedade atual (BRASIL, 2004c).

Tão importante quanto o saneamento urbano, o saneamento rural constitui-se na forma de promover ações na área de saúde, habitação e meio ambiente para garantir o acesso a serviços básicos de saneamento à população rural que, de acordo com o censo do Instituto Brasileiro de Geografia e Estatística (IBGE) de 2010, constitui-se em 29,8 milhões de pessoas, formada por quilombolas, assentados e comunidades rurais. 0 acesso a tais serviços de saneamento é escasso e observa-se que $25 \%$ do total da população rural do Brasil vive em extrema pobreza, contribuindo direta ou indiretamente para o surgimento de doenças de veiculação hídrica, parasitoses e diarreia (MARTELLI, 2013).

Diante dos fatos, o objetivo do presente trabalho é, por meio de uma pesquisa de revisão bibliográfica, verificar a situação acerca do saneamento básico no Brasil, com ênfase no saneamento rural.

\section{Saneamento básico e saúde}

De acordo com a Política Nacional de Saneamento Básico (BRASIL, 2007), saneamento básico é o conjunto de serviços, infraestruturas e instalações de abastecimento de água, esgotamento sanitário, limpeza urbana e manejo de resíduos sólidos e drenagem de águas pluviais urbanas.

Os efeitos do saneamento sobre a saúde e a qualidade de vida da população são amplos e infindáveis. Há tempos é reconhecido por diversas civilizações que sanear os diversos ambientes traz benefícios sobre o desenvolvimento humano da sociedade e o padrão de vida geral da população. Os benefícios abordam o aumento da qualidade ambiental com consequente diminuição de doenças infecciosas. Durante o início do século XX, os Estados Unidos iniciaram o processo de desinfecção com cloro na água de abastecimento, que resultou em significativa redução das taxas de morte por febre tifoide naquele país (FORMOSINHO, 2007).

De acordo com a Organização das Nações Unidas (ONU, 2015) e a Organização Mundial da Saúde (OMS), 2,4 bilhões de pessoas no planeta, ou uma em cada três, são desprovidas de saneamento básico. No ano de 2012 estimou-se que 748 milhões de pessoas ainda não tinham acesso a uma fonte de água potável. Além disso, grandes disparidades continuam a existir, não só entre as diferentes regiões do mundo, mas também entre áreas urbanas e rurais como também entre diferentes grupos socioeconômicos dentro dos países. Até aquele mesmo momento, no ano de 2012, aproximadamente 2,5 bilhões de pessoas ainda não tinham acesso a instalações sanitárias adequadas e 14 \% da população mundial 
(1 bilhão de pessoas) não tinham acesso a nenhuma forma de instalação sanitária, desse total 90 \% viviam em áreas rurais. Esse quadro geral pode conduzir a níveis elevados de contaminação ambiental e exposição aos riscos de infecções microbianas, doenças diarreicas, tracoma, esquistossomose e hepatite (WORLD HEALTH ORGANIZATION - WHO, 2015).

$\mathrm{O}$ acesso à água tratada e higiene são imprescindíveis para a prevenção e cuidados de doenças causadas pela precariedade dos serviços de saneamento. Entre elas destacam-se: diarreias, doenças dermatológicas, leishmanioses, malária, doença de Chagas, esquistossomose, lepra, febre tifoide, febre paratifoide, cólera, hepatite A, amebíase, giardíase, leptospirose, ancilostomíase (amarelão), ascaridíase (lombriga), teníase, cisticercose, filariose (elefantíase), dengue e mais recentemente zika e chikungunya.

Teixeira e Guilhermino (2006) realizaram uma análise entre saneamento e saúde nos estados brasileiros utilizando informações do Banco de Dados Indicadores e Dados Básicos para a Saúde do ano de 2003. Foi relatado que a mortalidade infantil, a mortalidade proporcional por doença diarreica aguda em menores de cinco anos de idade e a mortalidade proporcional por doenças infecciosas e parasitárias para todas as idades nos estados brasileiros encontravam-se associadas à inexistência ou precariedade dos serviços de saneamento.

Como um dos principais indicadores para avaliar a situação da saúde e a qualidade de vida de uma população, as estimativas da taxa de mortalidade infantil (TMI) são cruciais. O Brasil apresentou uma redução expressiva da taxa de mortalidade infantil no período de 1990 a 2012, passando de 47,1 óbitos infantis por 1.000 nascidos vivos (NVs) em 1990 para 14,6/1.000 NVs em 2012, significando uma redução de aproximadamente $70 \%$ neste período. Esta queda ocorreu em todas as regiões brasileiras, com destaque para o Nordeste, cuja taxa situava-se muito acima das demais regiões (BRASIL, 2014). Há consistente tendência de redução da mortalidade infantil em todas as regiões brasileiras, o que reflete a melhoria nas condições de vida e o efeito de intervenções públicas nas áreas de saúde, saneamento, entre outros. Ainda assim, os valores médios continuam elevados, sobretudo em algumas regiões, como mostram os Indicadores e Dados Básicos do ano de 2013 (BRASIL, 2013). Segundo esse documento, o estado de Roraima possui o pior índice com 7,4\% de óbitos por doença diarreica aguda em menores de 5 anos, seguido por Alagoas, Amazonas e Mato Grosso do Sul, com 6,7 \%, 5,6 \% e 4,0 \% respectivamente.

A doença diarreica é considerada um problema de saúde pública com alta morbimortalidade mundial. No Brasil entre 1995 e 2005 ocorreram 1.505 .800 internações e 39.421 óbitos de crianças menores de um ano, devido à diarreia e suas complicações (MENDES et al., 2013). Os dados gerados pela pesquisa dão ciência sobre a heterogeneidade regional dos coeficientes de mortalidade por diarreia descritos e refletem a desigualdade socioeconômico-cultural, assim como a dificuldade de acesso à saúde e ao saneamento.

Apesar desses vários registros sobre o decréscimo dos índices de mortalidade por diarreia no país, maiores esforços devem ser realizados para que possa ser reduzido ainda mais este indicador que ainda é consideravelmente alto em relação aos países desenvolvidos como observado em WHO (2015).

Políticas públicas que promovam a redução das diferenças sociais e que ampliem o acesso ao saneamento, estruturem os serviços de saúde, além de educação sanitária via informação, prevenção e tratamento, devem ser estabelecidas para o alcance de índices mais satisfatórios e qualidade de vida para a população. 


\section{Caracterização de zona rural e comunidades isoladas}

As definições existentes do que seja rural e urbano no Brasil e as análises da dinâmica demográfica, objetos de intensas controvérsias, de forma geral, não são devidamente trabalhadas nas formulações das políticas públicas, podendo implicar em limitações, inadequações e fracassos no conjunto de ações destinadas a estes espaços (SILVA; ZANCUN, 2012).

A definição do rural fica mais confusa quando se observam as novas características do campo, como a intensificação da pluriatividade, o aumento das atividades não agrícolas em áreas rurais, como serviços e indústrias, a mecanização crescente da atividade agropecuária, o agronegócio e os movimentos sócioterritoriais no campo. Segundo Reis (2006), a expansão do tecido urbano sobre as áreas rurais e o crescimento do número de pessoas ocupadas em atividades consideradas até então como exclusivamente urbanas indicam a existência de um novo paradigma sócioespacial no Brasil.

De acordo com a legislação vigente, os parâmetros quantitativos populacionais que permitem delimitar a divisão entre o espaço urbano e o rural não são estabelecidos, como exemplo, número mínimo de habitantes e densidade demográfica mínima. A delimitação do perímetro urbano está a cargo de cada administração municipal e não há um critério único nacional para estabelecer a fronteira entre o que é área urbana e o que é rural (COSTA; NARDELLI, 2009).

Até 1990, a maioria da população mundial, ou seja, 57 \% habitavam em áreas rurais, mas, desde então, a situação tem invertido, e em 2015 a proporção diminuiu para 46 \% (WHO, 2015). No Brasil, 30 milhões de pessoas residem em localidades rurais, representando aproximadamente $16 \%$ da população brasileira (IBGE/2010) e 8,8 milhões de domicílios rurais (PNAD/2009). Os estados que possuem a maior população rural são Minas Gerais, Bahia, Ceará, Maranhão e Pará, como podemos observar na figura 1.

Figura 1. Distribuição da População Rural por Estado

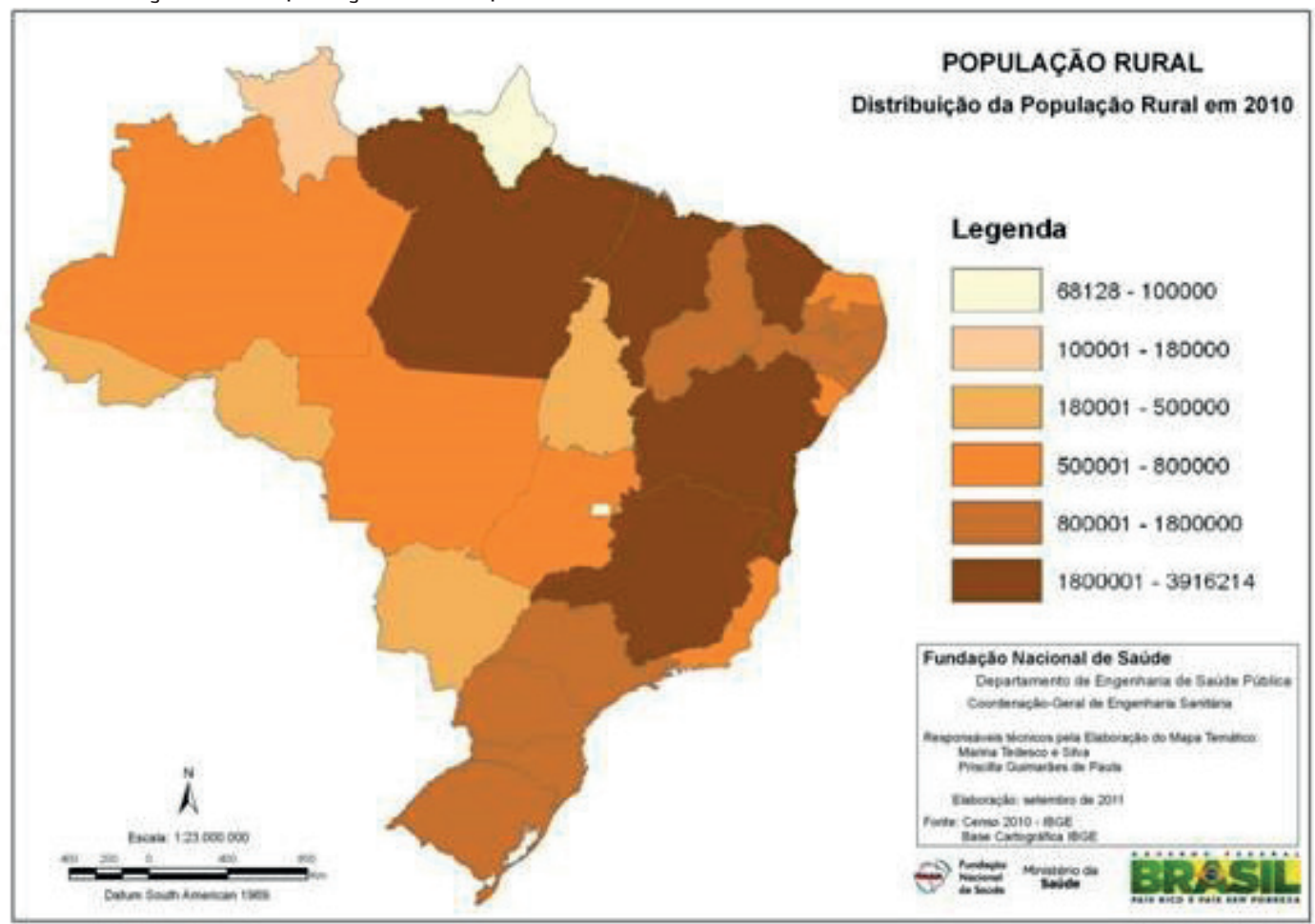

Fonte: IBGE - Censo (2010). 
Assim, as conveniências locais, como a definição da área urbana para fins de cobrança do Imposto Predial e Territorial Urbano (IPTU), passam a ser o parâmetro delimitador (COSTA; NARDELLI, 2009). O Imposto Territorial Rural (ITR), que está previsto no Código Tributário Nacional, refere-se ao tributo sobre a propriedade territorial rural para imóveis localizados fora da zona urbana, o que nos leva a entender que a definição de zona rural é um conceito dado por meio de exclusão, ou seja, compreende zona rural o que não for definido por lei municipal como zona urbana (SANTINI et al., 2009).

Há um projeto de lei de autoria do Senador Gilberto Goellner que altera a Lei $n^{\circ} 10.257$, de 10 de julho de 2001, denominada Estatuto da Cidade, para incluir critérios de classificação do espaço urbano e rural, porém esse foi arquivado em 2015. De acordo com tal projeto, os municípios estariam classificados em função do tamanho da população, da densidade demográfica e da composição do Produto Interno Bruto (PIB) municipal (COSTA; NARDELLI, 2009). O Instituto Brasileiro de Geografia e Estatística (IBGE), a partir dos novos critérios, faria a classificação dos municípios e atualizaria os dados. A classificação do município se restringiria a cinco níveis: rural, relativamente rural, de pequeno porte, de médio porte e de grande porte. As características que enquadrariam a localidade como rural seriam população inferior a 50 mil habitantes, valor adicionado da agropecuária superior a uma terça parte do PIB municipal e densidade demográfica inferior a 80 habitantes por quilômetro quadrado. Essa lei afetaria 4.957 municípios brasileiros, uma vez que 89,1 \% possuem até 50 mil habitantes, aproximadamente 33,6 \% da população, ou seja, 64 milhões de pessoas (IBGE, 2010).

Certamente torna-se necessário reavaliar os critérios que definem zona rural ou urbana, devendo esses significados serem tratados como adjetivos para as regiões, de modo que possam ser propostas políticas públicas de habitação e moradia, agrícolas, sanitárias, voltadas para cada espaço classificado como urbano ou rural. Um aspecto relevante nesse tema é a necessidade de conscientização de que é necessário elaborar estratégias diferenciadas que respeitem a identidade natural e social do lugar, prezando por uma visão mais sistêmica e não apenas do ponto de vista da infraestrutura (HOSOI, 2011).

A definição de comunidades isoladas consiste em loteamentos ou núcleos habitacionais localizados normalmente em áreas periféricas de cidades, ou comunidades, litorâneas ou não, de difícil acesso, cuja interligação aos sistemas principais de água e de esgotos do município sejam economicamente inviáveis e necessitem de soluções independentes desses serviços.

Sendo assim, cabe ressaltar que nem toda comunidade isolada é rural, o que na atualidade é um dos grandes desafios para o saneamento brasileiro. Nessa ótica, é primordial o desenvolvimento de um modelo sustentável para levar água potável e tratamento de esgoto às comunidades isoladas, por meio de soluções alternativas, que diminuam o custo do empreendimento, aliadas a políticas dos Estados com viabilização técnica e envolvimento da comunidade.

É claramente perceptível a necessidade de discussão acerca do conceito de rural a ser utilizado, principalmente no que tange à elaboração do Programa de Saneamento Rural, tornando-se indispensável para a delimitação do território de atuação, bem como para a definição de indicadores de cobertura e a proposição de metas e recursos para a implantação e gestão bem-sucedida do programa.

\section{Políticas públicas voltadas para o saneamento}

A legislação ambiental brasileira apresenta normas e regulamentações padronizadas que se aplicam diretamente a toda realidade rural com a suposição de um espaço homogêneo. Porém, a realidade mostra vários impedimentos para que tais políticas se concretizem, como características ecológicas espaciais muito distintas nas localidades, espaço rural com outras funções, além da ativi- 
dade agrícola e a existência de particularidades dos diferentes sistemas de produção praticados nas propriedades (NEUMANN; LOCK, 2002).

A legislação referente ao saneamento está relacionada também a outras políticas setoriais como a de meio ambiente, saúde, habitação, recursos hídricos, política agrária, política urbana, entre outras (REZENDE; HELLER, 2008). Entre as diversas interfaces entre as legislações, ressaltam-se aquelas que se tornaram marcos importantes para a construção de uma política de saneamento no Brasil.

Primeiramente, na Constituição Nacional de 1988 evidenciam-se dois incisos estabelecidos no artigo 21 que diz ser responsabilidade da União: inciso IX, "[...] elaborar e executar planos nacionais e regionais de ordenação do território e de desenvolvimento econômico e social [...]"; inciso XX, "[...] instituir diretrizes para o desenvolvimento urbano, inclusive habitação, saneamento básico e transportes urbanos [...]" (BRASIL, 1988).

As ações de saneamento básico estão diretamente vinculadas à gestão dos recursos hídricos, motivo pelo qual faz-se necessária a adoção de políticas de proteção e controle do meio ambiente. Nesse sentido, a Política Nacional de Meio Ambiente (PNMA) - Lei 6.938/1981, a Política Nacional de Recursos Hídricos (PNRH) - Lei 9.433/1997 - e a Lei de Crimes Ambientais - Lei 9.605/1998 - têm como principal objetivo instituir regras que tornem possível o desenvolvimento sustentável por meio de mecanismos e instrumentos capazes de conferir ao meio ambiente maior proteção. No arcabouço legal do Sistema Nacional de Meio Ambiente (SISNAMA), ressalta-se que o Conselho Nacional de Meio Ambiente (CONAMA), dentro das suas competências normativas e deliberativas, estabelece normas, resoluções e deliberações relativas ao controle e à manutenção da qualidade do meio ambiente com a finalidade de uso racional dos recursos ambientais, entre eles os recursos hídricos (CONAMA, 2005).

De acordo com a Política Nacional de Saneamento Básico (PNSB), os recursos hídricos não integram os serviços públicos de saneamento básico. Portanto, a utilização de recursos hídricos na prestação de serviços públicos de saneamento básico, inclusive para disposição ou diluição de esgotos e outros resíduos líquidos, é sujeita à outorga de direito de uso, de acordo com as premissas da PNRH, cabendo à Agência Nacional das Águas (ANA) e aos órgãos estaduais competentes a regulação dos serviços de saneamento básico, por meio da emissão de outorgas (de uso da água e de lançamento de efluentes) e dos Certificados de Avaliação da Sustentabilidade da Obra Hídrica, os chamados CERTOHs, assim como da cobrança pelo uso da água (BRASIL, 2016a).

Como observado, diversos são os dispositivos legais que norteiam a aplicação de políticas públicas voltadas para o saneamento. Porém, em muitos pontos, estes dispositivos não se integram. Desta forma, para que ocorra o ajustamento das políticas, foi estabelecida pela Lei do Saneamento a elaboração de um diagnóstico, o Plano Municipal de Saneamento Básico (PMSB), que traça ações e metas em um horizonte de 20 anos e identifica as condições e necessidades sanitárias locais para propor uma série de objetivos, estratégias, ações e programas que viabilizem a implantação de sistemas de saneamento.

Apesar dos esforços, a realidade mostra que $34 \%$ das maiores cidades brasileiras, o que representa $40 \%$ da população do país, não entregaram o PMSB, apesar de terem recursos financeiros, corpo técnico, estruturas políticas e conhecimento da Lei. O fato de que municípios deste porte não tenham seus Planos é extremamente alarmante (INSTITUTO TRATA BRASIL, 2016b).

No âmbito da saúde, na Lei 8.080 de 1990, é reconhecida a importância do saneamento, justificando que esse é um dos determinantes e condicionantes para expressar os níveis de saúde de 
um país (BRASIL, 1990). Tais níveis poderiam ser expressos por meio da utilização de indicadores epidemiológicos e de desenvolvimento social no planejamento, implementação e avaliação das suas ações de saneamento básico no país.

Um dos campos de atuação do Sistema Único de Saúde (SUS) é a participação na formulação da política e ações de saneamento básico, por meio de vigilância sanitária, vigilância epidemiológica, de saúde do trabalhador e de assistência terapêutica integral, inclusive farmacêutica. Tem como princípio a integração em nível executivo das ações de saúde, meio ambiente e saneamento básico para a melhoria das condições de saúde da população (BRASIL, 1990). Como exemplo, vale citar o Departamento de Engenharia de Saúde Pública (DENSP) da Funasa, que deve promover as melhorias sanitárias domiciliares, a cooperação técnica, estudos e pesquisas e ações de saneamento rural por meio de suas diversas coordenadorias, por exemplo, a Coordenadoria de Programas de Saneamento em Saúde (FUNDAÇÃO NACIONAL SAÚDE - FUNASA, 2016).

A integração entre as ações de saúde e de saneamento no Brasil está respaldada pela legislação vigente, porém colocar em prática a legislação tem sido uma dificuldade imensa para os governos, como exposto a seguir. O Atlas de Saneamento 2011, de autoria do IBGE, mostra que a média brasileira de internações por doenças relacionadas a problemas de saneamento diminuiu entre 1993 e 2008, passando de cerca de 750 a cada 100 mil habitantes para cerca de 300. No entanto, só em 2008, nos estados do Pará e Piauí, ocorreram de 900 a 1.200 internações para cada 100 mil habitantes - os piores índices entre os estados brasileiros nesse aspecto, seguidos pelo Maranhão, Rondônia e Paraíba, com números de internação entre 600 e 900 para cada 100 mil habitantes (JúNIA, 2011).

No contexto do setor de habitação, a Política Nacional de Habitação (PNH) assegura o direito a um padrão mínimo de habitabilidade, proporcionando infraestrutura, saneamento ambiental, mobilidade e transporte coletivo, equipamentos e serviços urbanos e sociais, como instrumentos de inclusão social. No meio rural é garantido o atendimento à população rural dispersa com soluções compatíveis com suas características regionais, socioambientais e culturais, as quais necessitam de forte presença do poder público local (BRASIL, 2004c). Porém, a política não condiz com a realidade, uma vez que $25 \%$ da população rural do Brasil vive em situação de pobreza extrema. Isso corresponde a um em cada quatro moradores do campo (IBGE, 2010).

De acordo com o Programa Aceleração do Crescimento (PAC), os investimentos na área têm como objetivo promover o acesso à moradia a partir de três programas na área habitacional integrantes da PNH: Programa Minha Casa Minha Vida, Urbanização de Assentamentos Precários e Financiamento Habitacional pelo Sistema Brasileiro de Poupança e Empréstimo (BRASIL, 2015). São investimentos realizados em parceria com governos estaduais, municipais, entidades urbanas e rurais e setor privado (BRASIL, 2015). Por suas características, escala e potencial, esses programas exigem uma participação efetiva do gestor local como parceiro indutor, articulador e estruturador da implantação da política habitacional nos municípios.

O Instituto Trata Brasil (2016b) afirmou que o PAC é o programa do governo com maiores recursos para redução dos déficits em saneamento no país, porém em pesquisa feita pelo órgão, os entraves à execução das obras estão relacionados a projetos mal elaborados, problemas nas licitações e burocracia nas licenças e desembolsos, o que acarreta atrasos ou paralisações nas obras. Esse contexto gerou um quadro em que das 112 obras do PAC 1, de 2017-2010, monitoradas há vários anos, apenas 19 delas ( $17 \%$ ) foram concluídas e na amostra total das 138 obras, que incluem as 26 obras do PAC 2, apenas $14 \%$ delas foram finalizadas. 
A partir de 2003, a lacuna institucional e a política do setor de saneamento básico começam a ser enfrentadas pelo governo federal. A tarefa central para a reestruturação do setor foi delegada ao Ministério das Cidades e coube à Secretaria Nacional de Saneamento Ambiental (SNSA) desse ministério coordenar as ações de saneamento básico, o que culminou com a aprovação da Lei no 11.445 em 2007 (PLANSAB, 2013).

Tal lei, denominada Lei de Diretrizes Nacionais para o Saneamento Básico (LDNSB), estabeleceu no artigo 52 que a União deverá elaborar, sob a coordenação do Ministério das Cidades, o Plano Nacional de Saneamento Básico - PLANSAB (BRASIL, 2007).

O PLANSAB é o eixo central da ação do Governo Federal dentro do setor e tem o papel articulador e orientador de esforços para atender às demandas de abastecimento de água, esgotamento sanitário, manejo de resíduos sólidos e de águas pluviais (FUNASA, 2011). Elaborado como forma de planejar o saneamento básico no país para os próximos 20 anos, o plano define a elaboração de três programas, Saneamento Básico Integrado, tendo como responsável o Ministério das Cidades; Saneamento Rural, com a supervisão do Ministério da Saúde por meio da FUNASA; Saneamento Estruturante do Ministério das Cidades (FUNASA, 2012).

Em 2004, no documento produzido pelo Ministério das Cidades, já se mencionava que "era expressivo o número de unidades habitacionais urbanas com algum tipo de carência de padrão construtivo, situação fundiária, acesso aos serviços e equipamentos urbanos, entre outros, o que revela a escassa articulação dos programas habitacionais com a política de desenvolvimento urbano, como a política fundiária, a de infraestrutura urbana e saneamento ambiental". Afirmava-se que no Brasil quase metade da população (83 milhões de pessoas) não era atendida por sistemas de esgotos; 45 milhões de cidadãos careciam de serviços de água potável. Nas áreas rurais, mais de $80 \%$ das moradias não eram servidas por redes gerais de abastecimento de água e quase 60 \% dos esgotos de todo o país eram lançados, sem tratamento, diretamente nos mananciais de água (BRASIL, 2004b).

Passados 10 anos, segundo o Sistema Nacional de Informações sobre o Saneamento, SINIS (2014), 82,5 \% dos brasileiros são atendidos com abastecimento de água tratada, 48,6 milhões têm acesso à coleta de esgoto e $40 \%$ dos esgotos são tratados. Contudo, quando as mesmas porcentagens são expressas em quantidades de habitantes, torna-se evidente a precariedade dos serviços, pois são mais de 35 milhões de pessoas sem água, mais de 100 milhões de pessoas sem esgoto e 1,2 bilhão de $\mathrm{m}^{3}$ de esgotos que foram lançados na natureza somente pelas capitais brasileiras no ano de 2013.

Dessa maneira, observam-se avanços, porém muito irrisórios para um país que tinha a meta de universalizar o saneamento até o ano de 2033, como previsto no Plano Nacional de Saneamento Básico, porém, de acordo com a Confederação Nacional de Indústria, haverá dificuldade para atingir a universalização até 2033, devendo o plano atrasar por no mínimo 20 anos (AMORA, 2016).

Em 2010, instituiu-se a Política Nacional de Resíduos Sólidos (PNRS), que tem como princípios a prevenção, precaução e o desenvolvimento sustentável, objetivando a proteção da saúde pública e qualidade ambiental (BRASIL, 2010b). Alguns aspectos importantes da lei podem ser ressaltados como a gestão integrada dos resíduos sólidos, a responsabilidade compartilhada, logística reversa e a inclusão social de catadores. Além desses, existem outros três pressupostos nesta política: a criação de metas que teoricamente contribuiriam para a eliminação dos lixões e a instituição de instrumentos de planejamento nos níveis nacional, estadual, microrregional, intermunicipal e metropolitano e municipal, como também a imposição para que particulares elaborem seus Planos de Gerenciamento de Resíduos Sólidos. 
Um grande obstáculo que contribui para que a política não se estabeleça de fato, mesmo com a legislação mais restritiva, é a destinação inadequada dos resíduos, ou seja, a existência irregular de lixões mesmo depois de encerrado o prazo previsto pela Lei. De acordo com a Associação Brasileira de Empresas de Limpeza Pública e Resíduos Especiais - ABRELPE (2014), em todas as regiões e estados brasileiros, a irregularidade se faz presente, pois 3.334 municípios, que correspondem a 59,8 \% do total, ainda fazem uso de locais impróprios para destinação final de seus resíduos. De acordo com a figura 2, dos resíduos sólidos urbanos coletados, 58,4 \% tiveram destinação adequada para aterros sanitários em 2014. Nesse sentido, é importante ressaltar que os 41,6 \% restantes correspondem a 81 mil toneladas diárias, que são encaminhadas para lixões ou aterros controlados, que não possuem o conjunto de sistemas e medidas necessários para proteção do meio ambiente.

Figura 2. Destinação de RSU (t/dia)

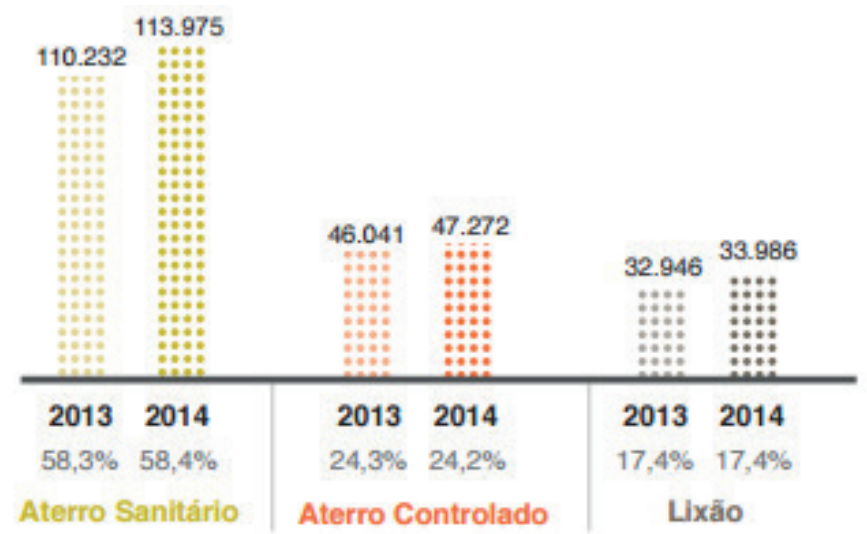

Fonte: Pesquisa ABRELPE (2014).

\section{Políticas Públicas para o Saneamento Rural}

Na Constituição Brasileira de 1988, o artigo 186, que faz alusão à função social da propriedade rural, afirma que tal função é cumprida quando a propriedade atende a quatro requisitos: aproveitamento racional e adequado; utilização adequada dos recursos naturais disponíveis e preservação do meio ambiente; observância das disposições que regulam as relações de trabalho; exploração que favoreça o bem-estar dos proprietários e dos trabalhadores (BRASIL, 1988).

De acordo com a Lei n 8.171, de 17 de janeiro de 1991, que dispõe sobre a política agrícola, um de seus pressupostos é que o processo de desenvolvimento agrícola deve proporcionar ao homem do campo o acesso aos serviços essenciais como saúde, educação, segurança pública, transporte, eletrificação, comunicação, habitação, saneamento, lazer e outros benefícios sociais.

O Brasil possui aproximadamente 31 milhões de habitantes que residem na área rural e comunidades isoladas, segundo dados do Instituto Brasileiro de Geografia e Estatística (IBGE, 2010). Ao contrário de ambas as leis citadas anteriormente que regem os direitos do homem do campo, desta população, somente 22 \% têm acesso a serviços adequados de saneamento básico e a realidade aponta que ainda existem quase 5 milhões de brasileiros que não possuem banheiro, ou seja, não possuem nenhum tipo de sanitário. Portanto, aproximadamente 24 milhões de brasileiros ainda sofrem com o problema crônico e grave da falta de saneamento básico (EMPESA BRASILEIRA DE AGROPECUÁRIA - EMBRAPA, 2016).

Em 2001, o Decreto 3.991/2001 que dispõe sobre o Programa Nacional de Fortalecimento da Agricultura Familiar (PRONAF) tinha por finalidade promover o desenvolvimento sustentável do meio 
rural, ou seja, prezava pela defesa do meio ambiente como um dos princípios da agricultura familiar (SIMÕES, 2015). Dessa maneira, surgiu o PRONAF Infraestrutura e Serviços Municipais no período 1997/2002 em parceria com os governos municipais. Entre os empreendimentos que poderiam beneficiar-se dos recursos dessa linha, estavam os ligados à recuperação de solos e implantação de sistemas de abastecimento de água e geração de energia, entre outros. Diversos problemas foram identificados para a implementação dessa linha de crédito entre os anos de 1997 e 2000, por exemplo, a escolha dos municípios, a vulnerabilidade do plano que atendia mais às exigências burocráticas do que às reais e principalmente a pouca experiência dos personagens envolvidos, como técnicos, líderes de associação e agricultores (ABRAMOVAY; VEIGA, 1999).

Os dois últimos problemas citados anteriormente são constantemente relatados como cruciais na aplicação de políticas de saneamento no Brasil. No art. $8^{\circ}$, que dispõe ainda sobre o PRONAF, é citado que o programa terá um Plano Anual de Ações que integrará o Plano Nacional de Desenvolvimento Rural Sustentável - PNDRS. Assim, de acordo com documento do Ministério do Desenvolvimento Agrário, o PNDRS é fruto de debate realizado entre as três esferas de governo e a sociedade no ano de 2013. O PNDRS traz objetivos, metas e iniciativas de curto, médio e longo prazo para o desenvolvimento rural brasileiro e representa um instrumento estratégico para a participação rural no desenvolvimento nacional (BRASIL, 2016b).

Em 2011 o governo brasileiro instituiu o Plano Brasil Sem Miséria por meio do Decreto $n^{\circ}$ 7.492/2011. Nesse contexto, foi criado o Programa Nacional de Universalização do Acesso e Uso da Água - "Água Para Todos". O Programa destina-se a promover nas Áreas Rurais a universalização do acesso à água para consumo humano e para a produção agrícola e alimentar, visando ao pleno desenvolvimento humano e à segurança alimentar e nutricional de famílias em situação de vulnerabilidade social (FUNASA, 2016b).

Em suma, algumas questões consideradas primordiais na concepção de desenvolvimento rural são: a função social da propriedade, a aplicação das leis trabalhistas no campo e a obediência à legislação ambiental. No entanto, o desenvolvimento rural ultrapassa as questões restritas ao ambiente rural, afetando e dependendo de uma interligação sempre existente com o meio urbano. Nesse sentido, a democratização dos processos de políticas públicas, com garantia de participação social nessas, contribui para a construção da ideia de desenvolvimento participativo e abrangente para o setor rural.

As políticas públicas voltadas para o desenvolvimento rural sustentável se estabelecem sempre tendo como referência a utilização adequada dos recursos naturais e preservação do meio ambiente, porém não há especificações que regem o saneamento rural.

O Programa Nacional de Saneamento Rural, proposto pelo Plano Nacional de Saneamento Básico, tem como objetivo universalizar o acesso às ações de saneamento básico nas áreas rurais, incluindo ações para abastecimento de água, esgotamento sanitário, melhorias sanitárias domiciliares, manejo de resíduos sólidos, educação e mobilização social. Para isso, o Programa, em elaboração, prevê um conjunto de procedimentos que garantam subsídios, sustentabilidade e participação social, a fim de alcançar metas de curto (2012-2015), médio e longo prazos, com investimentos estimados da ordem de R\$ 14 bilhões em 20 anos (FUNDAÇÃO NACIONAL DE SAÚDE - FUNASA, 2011).

O Programa é apoiado em três eixos estratégicos: tecnologia de saneamento apropriada a cada região; gestão, operação e manutenção dos serviços implantados; educação e mobilização social (ZANCUL; SALATI, 2014). A meta do programa são 20 anos, e os desafios são os mesmos de tempos atrás, a compreensão sobre as características e as necessidades das comunidades rurais nas diferentes regiões brasileiras; a conexão com outras políticas públicas e programas de governo, articulação entre Estado, municípios e sociedade civil. 
Depois do desafio de estabelecer um marco regulatório do saneamento no país e a aprovação da Política Nacional de Saneamento, Turolla (2002) afirmou que um segundo desafio para a universalização do saneamento no país seria criar uma legislação para regular o setor de saneamento, a qual poderia ser utilizada para criar fundos de universalização por área de concessão. A utilização de recursos públicos nesse contexto deveria direcionar-se exclusivamente às áreas em que o fundo de universalização não garante a autonomia do atingimento das metas de universalização em um prazo razoável.

\section{Panorama do saneamento rural no Brasil}

O número de pessoas que não contam com os serviços de saneamento ambiental em suas residências no Brasil é muito alto. Segundo o Atlas do Saneamento de 2011 do IBGE, além de deficiências nos sistemas de esgoto, existem também discrepâncias regionais em relação ao saneamento. A falta de sistemas de esgotamento sanitário atinge quase metade $(44,8 \%)$ dos municípios brasileiros. A Região Norte é a que apresenta a situação mais grave. Apenas 3,5 \% dos domicílios de $13 \%$ dos municípios da região têm acesso à rede coletora de esgoto. Essas diferenças também ocorrem em termos de serviços ofertados à população urbana e rural, em que a cada dez pessoas sem saneamento sete vivem em áreas rurais (VETTORE; LAMARCA, 2015).

A população rural do Brasil conta com uma elevada carência de serviços de saneamento, demonstrada por meio dos dados da Pesquisa Nacional por Amostra de Domicílios - PNAD (2014). Foi verificado que apenas 33,4 \% dos domicílios estão ligados a redes de abastecimento de água com ou sem canalização interna. Quando comparado ao PNAD-IBGE (2009), o número era de 32,8 \%, mostrando pequena evolução em cinco anos. No restante dos domicílios rurais (66,6 \%), a população capta água de chafarizes e poços protegidos ou não, de cursos de água sem tratamento algum ou de outras formas inadequadas para consumo humano. Observa-se também que 46,57 \% da parcela rural que não está ligada ao abastecimento de água por meio das redes, ou seja, que obtêm o abastecimento por meio de soluções alternativas, coletivas ou individuais, de abastecimento, possuem canalização interna e 20,01 \% sem canalização. Nesses casos, a qualidade da água depende da proteção das fontes e de uma rede de distribuição sem risco de contaminação.

Quanto ao abastecimento de água por região geográfica, a Região Nordeste apresenta maior percentual de domicílios rurais ligados à rede. Esse valor pode ser atribuído às suas características demográficas, pois 46,6 \% dos domicílios rurais brasileiros estão localizados nesta região. Conforme a discussão no tópico 3, o município é quem define se uma área é rural e o IBGE é legalmente obrigado a aceitar qualquer escolha realizada em âmbito municipal. Dessa maneira, a Região Nordeste possui a maior população rural e juntamente com o Norte continuam a ser as regiões mais pobres e, como em qualquer região, as áreas rurais em sua grande maioria, também são as mais pobres (SOARES et al., 2016). Além disso, a distribuição de seus domicílios é menos dispersa do que nas Regiões Norte e Centro-Oeste que apresentaram as menores taxas, 23,9\% e 15,3\% respectivamente (FUNASA, 2016).

Em relação aos Estados, notam-se diferenças consideráveis, como exemplo, o Estado de Mato Grosso, em que apenas $7 \%$ dos domicílios rurais estão ligados à rede de distribuição de água, enquanto em Sergipe esse percentual é cerca de 57 \% (FUNASA, 2016). O fato de alguns estados recorrerem a soluções alternativas de abastecimento, em detrimento da ligação à rede, deve-se a alguns fatores como: concentração de grandes propriedades e dispersão de domicílios, disponibilidade de água subterrânea, ausência ou insuficiência de sistemas públicos de abastecimento. Mato Grosso é o estado com maior percentual de domicílios rurais com soluções alternativas de abastecimento, 93 \% (FUNASA, 2016). 
Em relação ao esgotamento sanitário, os dados comprovam uma situação mais crítica quando comparado ao abastecimento de água. Segundo a PNAD (2014), apenas 57,6 \% dos domicílios brasileiros estão ligados diretamente à rede coletora. Quando a análise é focada em domicílios localizados em áreas rurais, esse quadro apresenta maior agravamento, somente 5,1 \% dos domicílios rurais possuem coleta de esgoto ligada à rede geral e $26,2 \%$ possuem fossa séptica (ligada ou não à rede coletora). Outro dado que chama a atenção é que 49,9\% dos domicílios utilizam fossa rudimentar e 11,4 \% não dispõem de nenhuma solução, índice que chama a atenção por referir-se à metade da totalidade dos domicílios rurais que apresentam destino incorreto para os dejetos. Esse fato pode ser explicado pelo grande número de domicílios dispersos e inexistência de redes coletoras nas áreas mais concentradas, o que leva os habitantes a recorrerem a processos alternativos para 0 esgotamento sanitário. Comparado ao dado de 2009 do PNAD, o número de domicílios rurais que possuíam fossa rudimentar era de 48,9 \%, mostrando que a conjuntura do problema não evoluiu.

Em todos os estados brasileiros, nas áreas rurais, a fossa rudimentar tem percentual muito acima dos outros tipos de destino, exceto na Região Sul, em que o valor quase se iguala à fossa séptica não ligada à rede coletora, aproximando-se de 50 \%, ao contrário do que se vê nas Regiões Norte e Nordeste com elevados percentuais de domicílios sem soluções para o esgotamento.

Referente à coleta de resíduos sólidos, o quadro é ainda mais discrepante, a PNAD (2014) apresentou que somente 27,0 \% dos domicílios rurais têm acesso à coleta direta de resíduos, contrastando com 92,2 \% dos domicílios urbanos. Quanto às regiões, é notório que nas Regiões Sudeste e Sul, há uma situação melhor em termos de coleta direta, 16 \% e 17,5 \% respectivamente, o que pode ser explicado pelo fato de as políticas públicas de limpeza urbana dessas regiões terem abrangência sobre as áreas rurais. Devido à dispersão dos domicílios rurais, não há como reproduzir no rural o modelo de coleta urbana, porém, avanços são necessários. Tradicionalmente, a fração orgânica dos resíduos sólidos é utilizada para alimentar animais ou disposta diretamente no solo, que, em ambientes naturais equilibrados, se degradam espontaneamente e reciclam os nutrientes nos processos da natureza (BRASIL, 2017). Ao mesmo tempo, a parte não orgânica, que era gerada em pequena quantidade, era reaproveitada e transformada em utensílios domésticos. Com o aumento do acesso aos bens industrializados vem crescendo a presença de resíduos não orgânicos e contaminantes no campo, como baterias, lâmpadas fluorescentes e embalagens de produtos químicos. Por este motivo, é importante que os municípios desenvolvam artifícios de coleta e tratamento, mesmo com uma frequência inferior àquela adotada em áreas urbanas, para atender os domicílios localizados em áreas rurais ou isoladas (MACHADO, 2014).

As estatísticas citadas anteriormente e a extrema desigualdade social existente no país tornam propício a existência de extensas áreas de pobreza com infraestrutura deficiente ou inexistente de saneamento e de saúde. Com base no IBGE de 2010, a população total em extrema pobreza no Brasil representa 16,2 milhões de habitantes e praticamente a metade encontra-se no meio rural, representando 7,6 milhões de habitantes, ou seja, $25 \%$ do total da população rural do Brasil. 0 estado que apresenta a maior porcentagem da população nessa situação é o Maranhão, seguido pelo Pará.

A consequência desse quadro é a potencialização e os altos índices de doenças de transmissão hídrica como parasitoses intestinais e diarreia além de mortalidade, mortalidade infantil e morbidade (BRASIL, 2004a). Outra consequência é a degradação dos recursos naturais, devido à exposição dos mananciais de abastecimento de água a fontes de contaminação pontuais e difusas.

Se os números são alarmantes nas grandes metrópoles, o problema é ainda mais complexo nas áreas rurais do país. Mesmo que se consiga cumprir as metas do Plano Nacional de Saneamento Bá- 
sico para resolver o problema até 2033, a previsão é que nas áreas rurais os indicadores chegariam, no máximo, a 77 \% da população com água potável e 62 \% com coleta de esgotos (CARLOS, 2016a).

Segundo dados da Funasa (2015), os recursos empenhados em Saneamento Rural, entre os anos de 2007 e 2014, foram da ordem de R\$ 794,5 milhões, em média R\$ 99,32 milhões/ano. Percebe-se que houve dois picos de investimentos demonstrados pelos anos de 2009 e 2012 com R\$ 141,1 milhões e R\$ 130,9 milhões, respectivamente. Por outro lado, em 2013 e 2014 foram registradas quedas em relação a 2012, com valores de $\mathrm{R} \$ 109,3$ milhões e $\mathrm{R} \$$ 83,0 milhões, respectivamente.

O Instituto Trata Brasil e a Fundação Getúlio Vargas (2010) obtiveram, por meio de um estudo realizado em conjunto, números muito interessantes diante de uma universalização do saneamento. O documento destaca queda de quase metade de internações por infecções gastrointestinais pelo SUS por crianças abaixo de 14 anos, chegando à economia de R\$ 745 milhões ao longo dos anos, o que traduz em 13,3 \% a mais de rendimento por trabalhador com aumento da sua renda média, valorização média de até 18 \% no valor dos imóveis, criação de 120 mil novos cargos de trabalho com um aumento no PIB de 1,9 bilhão no setor de turismo.

Porém a tão almejada universalização do acesso ao saneamento básico encontra diversos entraves, que justifica o porquê de ser uma meta tão difícil de ser alcançada no país. Entre eles destacam-se os projetos feitos sem o devido preparo técnico; investimentos e recursos insuficientes com consequente estagnação e atrasos, prestação de serviço inadequada e não cumprimento de metas; procedimentos burocráticos para acesso aos recursos e execução dos empreendimentos; divisão de competências e pulverização de ações e recursos judiciais; projetos de engenharia desatualizados, imprecisos e mal estruturados; despreparo técnico e financeiro de muitos dos operadores e principalmente a dificuldade dos municípios em acessar recursos devido à falta de capacidade de endividamento e incapacidade técnica em muitos casos (CARLOS, 2016b).

Diante dos números citados no presente tópico, fica claro que o Brasil encontra-se em uma situação alarmante e que a universalização dos serviços é uma realidade muito distante. Ao mostrar dados tão contrastantes das regiões, é reafirmado o descaso de investimentos do poder público, como também as desigualdades sociais, tão intrínsecas na sociedade brasileira.

\section{Considerações Finais}

Por muitos anos no Brasil, os investimentos na área de saneamento foram tímidos e como consequência o crescimento das cidades e comunidades rurais ficaram defasadas, acarretando até os dias de hoje problemas na área de infraestrutura e serviços, com consequentes reflexos negativos na saúde da população.

Apesar da criação do Plano Nacional de Saneamento Básico, há uma grande dificuldade dos governos em colocar em prática o que foi estabelecido por lei, seja por falta de capacitação dos muitos atores envolvidos, excesso de burocracias no setor público, não cumprimento de metas por parte dos governos, desvios de recursos, até a ausência da comunidade na participação dos planos e cobrança nas execuções dos mesmos. Esses entraves tornam as metas dos planos do governo sem perspectivas de se concretizarem.

O saneamento rural centralizado no país torna-se uma realidade longe de ocorrer devido à complexidade da baixa concentração de pessoas em uma mesma área, o que torna inviável a construção das tradicionais redes de coleta e tratamento de esgoto e distribuição de água. A baixa porcentagem de pesquisas na área dificulta a criação de políticas e tecnologias de baixo custo que atendam às 
reais necessidades particulares dessa população tão diversa que é a do campo. No âmbito da executabilidade, é necessário o treinamento de agentes capacitados que qualifiquem pessoas nas próprias comunidades rurais ou isoladas com o intuito de gerir seus próprios sistemas de saneamento.

Há urgência para que ocorra uma gestão associada e integrada entre as esferas municipal, estadual e federal para que as metas do plano nacional sejam cumpridas no menor prazo possível do objetivo proposto e com qualidade nos serviços. A difusão do conhecimento sobre saneamento como direito constitucional, seus benefícios e implicações são de relevante importância para integrar a comunidade na construção participativa dos Planos Municipais, com o objetivo de que as demandas da sociedade se tornem reais.

O reconhecimento e incentivo do homem do campo como protetor dos recursos ambientais, a educação ambiental e a sanitária e investimentos em saúde preventiva são verdadeiros propulsores para a tão almejada universalização do saneamento no país e a reafirmação da cidadania.

\section{Sanitation in rural Brazilian context}

\section{Abstract}

The natural resource exploitation and the increasing generation of by-products bring harmful consequences for man and the environment. Sanitation is one way to put things right, because it promotes environmental health through water supply, waste collection, correct land use, urban drainage, among others, in order to improve urban and rural life conditions. The rural areas need knowledge about their reality since it is characterized by populations with less access to reorganization measures, with $25 \%$ of its population living in extreme poverty. Over the years there have been created various public policies in order to universalize the access to sanitation actions. Thus, the present article, through a literature review, discusses the situation of basic sanitation in Brazil, with emphasis on rural sanitation. For that, relevant information of key public and private agencies and academia documents were used as sources of information. We conclude the tendency is that rural sanitation is built slower than in urban areas due to the low concentration of people in the same area; also, it is necessary to consider the knowledge about sanitation a constitutional right, therefore it can become an integrated construction in which the company is active in promoting improvements in quality of life.

Keywords: Isolated communities. Health. Salubrity.

\section{Referências}

ABRAMOVAY, R.; VEIGA, J. E. Novas instituições para o desenvolvimento rural: o caso do Pronaf. Brasília: IPEA, 1999; 51p. Disponível em: <http://repositorio.ipea.gov.br/bitstream/11058/2617/1/ td_0641.pdf>. Acesso em: 26 maio 2016.

AMORA, D. Plano de saneamento do Brasil vai sofrer atraso de pelo menos 20 anos. FOLHA DE SÃO PAULO (jornal eletrônico). 2016. Disponível em: <http://www1.folha.uol.com.br/ mercado/2016/01/1727996-plano-de-saneamento-do-brasil-vai-sofrer-atraso-de-pelo-menos-20anos.shtml>. Acesso em: 29 mar. 2016. 
ASSOCIAÇÃO BRASILEIRA DE EMPRESAS DE LIMPEZA PÚBLICA E RESÍDUOS ESPECIAIS (ABRELPE). Panorama dos resíduos sólidos no Brasil, 2014. Disponível em: <http://www.abrelpe. org.br/Panorama/panorama2014.pdf>. Acesso em: 17 maio 2016.

BRASIL. Constituição da República Federativa do Brasil de 1988. Disponível em: <http://www. planalto.gov.br/ccivil_03/Constituicao/Constituicao.htm >. Acesso em: 27 fev. 2016.

BRASIL. Lei $n^{\circ} \mathbf{8 . 0 8 0}$, de 19 de setembro de 1990. Dispõe sobre condições para a promoção, proteção e recuperação da saúde, a organização e o funcionamento dos serviços correspondentes e dá outras providências. Disponível em: <http://www.planalto.gov.br/ccivil_03/leis/L8080.htm>. Acesso em: 29 fev. 2016.

BRASIL. Lei $\mathbf{n}^{\circ}$ 8.171, de 17 de janeiro de 1991. Dispõe sobre a Política Agrícola. Disponível em: <http://www.planalto.gov.br/ccivil_03/leis/L8171.htm>. Acesso em: 14 maio 2016.

BRASIL. Lei $\mathrm{n}^{\circ} 11.445$, de 5 de janeiro de 2007. Estabelece diretrizes nacionais para o saneamento básico; altera as Leis nos 6.766, de 19 de dezembro de 1979, 8.036, de 11 de maio de 1990, 8.666, de 21 de junho de 1993, 8.987, de 13 de fevereiro de 1995; revoga a Lei no 6.528, de 11 de maio de 1978; e dá outras providências. Disponível em: <http://www.planalto.gov.br/ccivil_03/_ ato2007-2010/2007/lei//11445.htm>. Acesso em: 14 maio 2016.

BRASIL. Lei $\mathrm{n}^{\circ}$ 12.305, de 2 de agosto de 2010. Institui a Política Nacional de Resíduos Sólidos; altera a Lei $n^{\circ}$ 9.605, de 12 de fevereiro de 1998; e dá outras providências. 2010 b. Disponível em: <http://www.planalto.gov.br/ccivil_03/_ato2007-2010/2010/lei/l12305.htm>. Acesso em: 29 fev. 2016.

BRASIL. Ministério da Saúde. Organização Pan-Americana da Saúde. Avaliação de impacto na saúde das ações de saneamento: marco conceitual e estratégia metodológica. Brasília: Ministério da Saúde, 116p, 2004a. Disponível em: <http://www.funasa.gov.br/site/wp-content/files_mf/eng_impacto. pdf>. Acesso em: 8 mar. 2016.

BRASIL. Ministério da Saúde. Secretaria de Vigilância em Saúde. Saúde Brasil 2013: uma análise da situação de saúde e das doenças transmissíveis relacionadas à pobreza. Brasília: Ministério da Saúde, 2014. 384p. Disponível em: <http://bvsms.saude.gov.br/bvs/publicacoes/saude_brasil_2013_ analise_situacao_saude.pdf >. Acesso em: 9 jun. 2016.

BRASIL. Ministério das Cidades. Política Nacional de Habitação. Brasília: Ministério das Cidades, 2004b. 104p. Caderno MCidades Habitação. Disponível em: < http://www.cidades.gov.br/images/ stories/ArquivosSNH/ArquivosPDF/4PoliticaNacionalHabitacao.pdf>. Acesso em: 8 mar. 2016.

BRASIL. Ministério do Desenvolvimento Agrário. Plano Nacional de Desenvolvimento Rural Sustentável e Solidário. Brasília: Ministério do Desenvolvimento Agrário. 2016b. Disponível em: <http://www.mda.gov.br/pndrss/>. Acesso em: 23 maio 2016.

BRASIL. Ministério do Meio Ambiente. Plano Nacional de Saneamento Básico. Brasília: Ministério do Meio Ambiente, 2016a. Disponível em: <http://www.mma.gov.br/component/k2/item/485-planonacional-de-saneamento-b\%C3\%A1sico>. Acesso em: 23 maio 2016. 
BRASIL. Ministério da Saúde. Departamento de Informática do SUS. Indicadores e Dados Básicos Brasil - 2013 - Informações de Saúde: indicadores de mortalidade. 2013. Disponível em: <http:// tabnet2.datasus.gov.br/cgi/tabcgi.exe?idb2013/c06.def>. Acesso em: 9 jun. 2016.

BRASIL. Ministério das Cidades. Secretaria Nacional de Saneamento Ambiental. Plano Nacional de Saneamento Básico (PLANSAB): mais saúde com qualidade de vida e cidadania. Brasília: Ministério das Cidades, 173p, 2013. Disponível em:<http://www.mma.gov.br/port/conama/processos/ AECBF8E2/Plansab_Versao_Conselhos_Nacionais_020520131.pdf>. Acesso em: 23 maio 2016.

BRASIL. Ministério do Planejamento. $1^{\circ}$ Balanço do Pac 2015. 2015. Disponível em: <http://www. pac.gov.br/pub/up/relatorio/ccedac8ebd8bfe1fefc25c0e4e4e8c0c.pdf>. Acesso em: 24 maio 2016.

BRASIL. Ministério do Meio Ambiente. Gestão de Resíduos Orgânicos. 2017. Disponível em: <http:// www.mma.gov.br/cidades-sustentaveis/residuos-solidos/gest\%C3\%A3o-de-res\%C3\%ADduosorg\%C3\%A2nicos>. Acesso em: 16 mar. 2017.

BRUNNER, P. H.; RECHBERGER, H. Waste to energy-key element for sustainable waste management. Vienna University Technology. Institute for Water Quality. Resource and Waste Management. v. 37, p 3-12, mar. 2015.

CARLOS, E. Instituto Trata Brasil. Saneamento: duas décadas de atraso. 2016a. Disponível em: <http://www.tratabrasil.org.br/saneamento-duas-decadas-de-atraso>. Acesso em: 29 mar. $2016 a$.

CARLOS, E. Instituto Trata Brasil. Saneamento rural: um enorme desafio para o Brasil. 2016b. Disponível em: <http://www.tratabrasil.org.br/saneamento-rural-um-enorme-desafio-para-o-brasilportal-do-saneamento>. Acesso em: 29 mar de 2016.

CARVAlHO, A. R.; OLIVEIRA, M. V. C. Princípios Básicos do Saneamento do Meio 211 p. 9.ed. São Paulo: Editora Senac, 2007.

CONSELHO NACIONAL DO MEIO AMBIENTE (CONAMA). Resolução n 357, de 17 de março de 2005. Dispõe sobre a classificação dos corpos de água e diretrizes ambientais para o seu enquadramento, bem como estabelece as condições e padrões de lançamento de efluentes, e dá outras providências. Disponível em: <http://www.mma.gov.br/port/conama/legiabre.cfm?codlegi=459>. Acesso em: 29 mar. 2016.

COSTA, D.; NARDELLI, R. Senado Federal. Criados critérios de classificação do espaço urbano e rural. 2009. Disponível em: <http://www12.senado.leg.br/noticias/materias/2009/10/06/criadoscriterios-de-classificacao-do-espaco-urbano-e-rural>. Acesso em: 25 maio 2016.

EMPRESA BRASILEIRA DE PESQUISA AGROPECUÁRIA (EMBRAPA). Saneamento básico rural. Disponívelem: <https://www.embrapa.br/tema-saneamento-basico-rural> . Acessoem: 19maio2016.

FORMOSINHO, S. Nos Bastidores da Ciência 20 anos Depois. Coimbra: Imprensa da Universidade de Coimbra, 2007. 454p. Disponível em: <https://books.google.com.br/books?id=ONb3bmzAzXkC\& $\mathrm{pg}=\mathrm{PA} 83 \& \mathrm{lpg}=\mathrm{PA} 83 \& \mathrm{dq}=$ estados + unidos $+\% 2 \mathrm{~B}+$ desinfec $\% \mathrm{C} 3 \% \mathrm{~A} 7 \% \mathrm{C} 3 \% \mathrm{~A} 30+$ com + cloro $+\% 2 \mathrm{~B}$ + febre+tif\%C3\%B3ide\&source $=$ bl\&ots $=x f 0 w 5 v M-g l \& s i g=4 A y t B k j V b 3 P m I V I-o s n s V x h 24 B M \& h l=p t B$ $\mathrm{R} \& s a=X \& v e d=0 a h U K E w i 470 v W g c z S A h W F D p A K H S m u D \_E Q 6 A E I R z A I \# v=$ onepage\&q=estados $\% 20$ unidos\%20\%2B\%20desinfec\%C3\%A7\%C3\%A30\%20com\%20cloro\%20\%2B\%20febre\%20 tif\%C3\%B3ide\&f=false $>$. Acesso em: 15 mar. de 2017. 
FUNDAÇÃO NACIONAL DE SAÚDE (FUNASA). Panorama do Saneamento Rural no Brasil. 2017. Disponível em: <http://www.funasa.gov.br/site/engenharia-de-saude-publica-2/saneamento-rural/ panorama-do-saneamento-rural-no-brasil/>. Acesso em: 15 maio 2016.

FUNDAÇÃO NACIONAL DE SAÚDE (FUNASA). Manual de Saneamento. 3.ed. rev. 408p. Brasília: Fundação Nacional de Saúde, 2004c.

FUNDAÇÃO NACIONALDESAÚDE(FUNASA). Saneamento rural. 2016a. Disponível em: <http://www. funasa.gov.br/site/engenharia-de-saude-publica-2/saneamento-rural/\#>. Acesso em: 26 fev. 2016.

FUNDAÇÃO NACIONAL DE SAÚDE (FUNASA). Ações de Saneamento Rural-Funasa. 2016b. Disponível em: <http://www.funasa.gov.br/site/engenharia-de-saude-publica-2/saneamento-rural/ acoes-de-saneamento-rural-funasa/> . Acesso em: 01 mar. 2016.

FUNDAÇÃO NACIONAL DE SAÚDE (FUNASA). Saneamento rural: o desafio de universalizar o saneamento rural. Boletim Informativo. Ed. 10, 2011. Disponível em: <http://www.funasa.gov.br/ site/wp-content/files_mf/blt_san_rural.pdf>. Acesso em: 01 mar. 2016.

HOSOI, C. Comunidades isoladas exigem um saneamento sob medida: A garantia de um futuro viável para as próximas gerações está cada vez mais associada ao conceito de sustentabilidade, inclusive na área de saneamento básico. Revista DAE, n. 187, 73p., set. 2011. Disponível em: < http://abes-sp. org.br/arquivos/revista_dae_187.pdf>. Acesso em: 25 maio 2016.

INSTITUTO BRASILEIRO DE GEOGRAFIA E ESTATÍSTICA (IBGE). Indicadores Sociais Municipais 2010. Disponível em: <http://www.ibge.gov.br/home/presidencia/noticias/imprensa/ppts/00000006 475711142011571416899473.pdf>. Acesso em: 26 maio 2016.

INSTITUTO TRATA BRASIL. 0 que é saneamento? 2018. Disponível em: <http://www.tratabrasil. org.br/o-que-e-saneamento>. Acesso em: 26 maio 2016a.

INSTITUTO TRATA BRASIL \& FUNDAÇÃO GETÚLIO VARGAS. Rio de Janeiro: Trata Brasil-FGV, 2010. 32p. Disponível em: <http://www.tratabrasil.org.br/novo_site/cms/files/trata_fgv.pdf> . Acesso em: mar. 2016.

INSTITUTO TRATA BRASIL. Maioria das obras de esgoto do PAC está paralisada e avanços seguem tímidos. Disponível em: <http://www.tratabrasil.org.br/maioria-das-obras-de-esgoto-do-pac-estaparalisada-e-avancos-seguem-timidos $>$. Acesso em: 17 maio 2016b.

JÚNIA, R. Escola Politécnica de Saúde Joaquim Venâncio. Brasileiros ainda adoecem por falta de saneamento básico. 2011. Disponível: <http://www.fiocruz.br/omsambiental/cgi/cgilua.exe/sys/ start.htm?infoid $=262 \&$ sid $=13>$. Acesso em: 15 maio 2016.

MACHADO, B. G. A coleta e o transporte dos resíduos sólidos no Brasil. 2014. Disponível em: <http://www. portalresiduossolidos.com/a-coleta-e-o-transporte-dos-residuos-solidos-no-brasil/> . Acesso em: 24 maio 2016.

MARTELLI, F. H. "Saneamento básico e qualidade das águas - Conceitos fundamentais, principais doenças disseminadas pela água. Principais indicadores biológicos da qualidade da água". 2013. São Carlos: Prefeitura de São Carlos. Disponível em: <http://saneamento.cnpdia.embrapa.br/downloads/Conceitos_ fundamentais,_principais_doen\%C3\%A7as_disseminadas___Fabricio.pdf>. Acesso em: 30 mar. 2016. 
MENDES, P. S.; RIBEIRO, J. R. H. C.; MENDES, C. M. Temporal trends of overall mortality and hospital morbidity due to diarrheal disease in Brazilian children younger than 5 years from 2000 to 2010. Jornal de Pediatria, Porto Alegre, v. 89, n. 3, p. 315-325, maio/jun.2013. Disponível em: <http://www.scielo.br/scielo.php?script=sci_arttext\&pid=S0021-75572013000300015>. Acesso em: fev. 2016.

NEUMANN, P. S.; LOCK, C. Legislação Ambiental, desenvolvimento rural e práticas agrícolas. Ciência Rural, Santa Maria, v. 32, n. 2, p. 243-249, 2002. Disponível em: <http://www.scielo.br/scielo. php?script=sci_arttext\&pid=S0103-84782002000200010 > . Acesso em: mar. 2016.

ORGANIZAÇÃO DAS NAÇÕES UNIDAS (ONU). Desenvolvimento Sustentável. Mais de 2 bilhões de pessoas não têm saneamento básico, afirma novo relatório da ONU. 2015. Disponível em: <http:// nacoesunidas.org/mais-de-2-bilhoes-de-pessoas-no-planeta-carecem-de-saneamento-basico-onu/> . Acesso em: 03 mar. 2016.

REIS, D. S. O rural e urbano no Brasil. Encontro Nacional de Estudos Populacionais, 15, 2012. Anais... Disponível em: <http://www.abep.org.br/publicacoes/index.php/anais/article/view/1492/1457> . Acesso em: 23 maio 2016.

REZENDE, S. C.; HELLER, L. 0 saneamento no Brasil: políticas e interfaces. 2. ed. rev. e ampl. 387p, Belo Horizonte: Editora UFMG, 2008.

SANTINI, J. C. L.; FRANÇA, L. M. C.; NECCHI, L. C. C. IPTU X ITR: conflito entre os critérios espaciais. Revista de Direito Público, Londrina, v. 4, n. 1. p. 125-139, jan/abr. 2009. Disponível em: <http:// www.uel.br/revistas/uel/index.php/direitopub/article/view/10738/9383>. Acesso em: mar. 2016.

SIMÕES, D. Entenda o Programa de Fortalecimento da Agricultura Familiar (Pronaf). 2015. Disponível em: <http://www.brasil.gov.br/economia-e-emprego/2015/08/entenda-o-programa-defortalecimento-da-agricultura-familiar-pronaf> . Acesso em: 23 maio 2016.

SILVA, E. R.; ZANCUL, J. S. Análise da Dinâmica Demográfica Rural Brasileira como Estratégia na Formulação da Política Federal de Saneamento Rural. In: ENCONTRO NACIONAL DE ESTUDOS POPULACIONAIS, 2012, 18. Águas de Lindóia/SP: ABEP, 2012. 22p. Anais... Disponível em: <http://www.abep.org.br/publicacoes/index.php/anais/article/view/1961/1919>. Acesso em: mar. 2016.

SOARES, S.; SOUZA, L.; SILVA, W. J.; SILVEIRA, F. G.; CAMPOS, A. Perfil da pobreza: norte e nordeste rurais. Brasília: International Policy Centre for Inclusive Growth, 2016. 44p. (IPC-IG Working Paper n. 138). Disponível em: <http://www.ipc-undp.org/pub/port/PRB50PT_Perfil_da_pobreza_Norte_e_ Nordeste_rurais.pdf>. Acesso em: 16 mar. 2017.

TEIXEIRA, J. C.; GUILHERMINO, R. L. Análise da associação entre saneamento e saúde nos estados brasileiros, empregando dados secundários do banco de dados Indicadores e Dados Básicos para a Saúde - IDB 2003. Revista de Engenharia Sanitária e Ambiental, v. 11, n. 3, p. 277-282, 2006. Disponível em: $\quad$ <http://www.scielo.br/scielo.php?script=sci_arttext\&pid=S1413-41522006000300011>. Acesso em: jan. de 2016. 
TUROLlA, F. A. Política de saneamento básico: avanços recentes e opções futuras de políticas públicas. Brasília: Instituto de Pesquisa Econômica e Aplicada, 29p., 2002. Disponível em: <http:// ipea.gov.br/agencia/images/stories/PDFs/TDs/td_0922.pdf>. Acesso em: 03 mar. 2016.

VETTORE, M.; LAMARCA, G. Determinantes Sociais da Saúde e do Bem Estar. 2015. Disponível em: $\quad<$ http://dssbr.org/site/2012/01/censo-2010-uma-leitura-dos-resultados-sobresaneamento-basico/>. Acesso em: 03 mar. 2016.

WORLD HEALTH ORGANIZATION (WHO). World Health Statistics 2015. 164p. Disponível em: <http://www.who.int/gho/publications/world_health_statistics/EN_WHS2015_Part1.pdf?ua=1 > . Acesso em: 26 maio 2016.

ZANCUL, J.; SALATI, D. Programa Nacional de Saneamento rural: atuação da FUNASA e perspectivas. In: VII SEMINÁRIO NACIONAL DE SANEAMENTO RURAL. II ENCONTRO LATINO-AMERICANO DE SANEAMENTO RURAL, 2014, Brasília: FUNASA, 2014. 41p. Disponível em: <http://abes-sp.org. br/arquivos/viissr/atuacao-da-funasa-e-perspectivas-juliana-zancul-funasa.pdf $>$. Acesso em: 01 mar. 2016.

\section{Histórico editorial:}

Submetido em: 17/06/2016

Aceito em: 17/03/2017

Como citar:

ABNT

RESENDE, R. G.; FERREIRA, S.; FERNANDES, L. F. R. O saneamento rural no contexto brasileiro. Revista Agrogeoambiental, Pouso Alegre, v. 10, n. 1, p. 129-150, jan./mar.

Doi: http://dx.doi.org/10.18406/2316-1817v10n120181027

APA

RESENDE, R. G., FERREIRA, S. \& FERNANDES, L. F. R. (2018). 0 saneamento rural no contexto brasileiro. Revista Agrogeoambiental, 10 (1), 129-150. Doi: http://dx.doi.org/10.18406/2316-1817v10n120181027

$\underline{\text { ISO }}$

RESENDE, R. G.; FERREIRA, S. e FERNANDES, L. F. R. O saneamento rural no contexto brasileiro. Revista Agrogeoambiental, 2018, vol. 10, n. 1, pp. 129-150. Eissn 2316-1817.

Doi: http://dx.doi.org/10.18406/2316-1817v10n120181027

VANCOUVER

Resende RG, Ferreira S, Fernandes LFR. O saneamento rural no contexto brasileiro. Rev agrogeoambiental. 2018 jan/mar; 10(1): 129-150. Doi: http://dx.doi.org/10.18406/2316-1817v10n120181027 